\title{
PENERAPAN METODE TERM FREQUENCY (TF) - INVERS DOCUMENT FREQUENCY (IDF) UNTUK PENCARIAN SINONIM KATA DALAM KAMUS BAHASA DAYAK GAJU KALIMANTAN TENGAH
}

\author{
Devi Karolita $^{\mathrm{a}, 1, *}$, Ade Chandra Saputra ${ }^{\mathrm{b}, 2}$ \\ a Jurusan Teknik Informatika FT UPR, Jl H. Timang Tunjung Nyaho \\ ${ }^{\mathrm{b}}$ Jurusan Teknik Informatika FT UPR, Jl H. Timang Tunjung Nyaho \\ ${ }^{1}$ devikarolita@it.upr.ac.id*; ${ }^{2}$ adechandra@it.upr.ac.id \\ * corresponding author
}

\section{ARTICLE INFO}

\section{Keywords}

TF-IDF, dictionary

Bahasa Dayak Ngaju

\section{ABSTRACT}

The available Bahasa Dayak Ngaju dictionary only in hardcopy form and only consisted of the list of words and the meaning of them. The dictionary didn't provide the synonym of the word we are looking for. If we want to know the paraphrase of one particular word, we have to do it manually by searching it on all of the list of words in the dictionary. Therefore, this research proposed to develope a Dayak Ngaju dictionary that provide word synonym search. We use Term Frequency (TF) - Invers Document Frequency (IDF) algorithm that will help synonym searching by comparing the term emergence in the meaning of the word that we are going to look the synonym for in all of the meaning of the words listed on the dictionary. This method will calculate the weight in all the documents based on the input query. To evaluate the methodology accuracy, we used precision and recall method. The results showed that after searching synonym of 100 queries, we founded that 33 queries had synonyms with precision $=1$ and recall $=1$ and all the synonyms that are found are relevant based on expert's justification.

\section{Pendahuluan}

Salah satu media komunikasi yang saat ini berkembang pesat adalah media internet. Karena dengan mengakses internet informasi apapun yang dibutuhkan dapat diperoleh dengan cepat. Sehingga tidak heran jika aktivitas sehari-hari masyarakat pada umumnya sekarang bergantung pada internet. Internet dimanfaatkan sebagai media untuk belajar, bisnis, gaya hidup dan lain sebagainya. Untuk pembelajaran di internet tersedia begitu banyak e-book, dan jurnal yang dapat di diperoleh atau di download tanpa harus membeli buku karena lebih murah dan cepat mendapatkannya.

Banyak website yang menyediakan jenis kamus-kamus online yang jauh lebih efektif dan cepat daripada menggunakan kamus berupa buku. Kamus adalah buku acuan yang memuat kata dan ungkapan yang biasanya disusun menurut abjad berikut keterangan maknanya, pemakaiannya dan terjemahannya. Kamus biasanya berguna untuk seseorang yang ingin belajar bahasa atau kata-kata baru.

Kamus Dayak Ngaju yang banyak diterbitkan hanya berupa buku kamus. Dan kamus tersebut hanya berisi daftar arti-arti kata atau terjemahannya ke bahasa indonesia. Demikian juga dalam mencari sinonim sangat sulit karena harus mencari satu per satu di dalam kamus yang isinya tidak teratur. Sinonim kata adalah ungkapan (kata, frasa, atau kalimat) yang kurang lebih sama maknanya dengan ungkapan yang lain.

Dari permasalah diatas maka perlu dibuat aplikasi (software) bahasa Dayak Ngaju yang dapat melakukan pencarian sinonim. Dalam pencarian sinonim kata diperlukan sistem yang dapat menentukan dokumen yang paling tepat di antara dokumen-dokumen yang mengandung kata yang 
dicari. Dalam melakukan pencarian sinonim kata ini digunakan metode Term Frequency (TF) - Invers Document Frequency (IDF). Dimana sistem ini memperhitungkan bobot pada setiap dokumen berdasarkan query yang dimasukan oleh pengguna sistem dan menampilkan hasil yang paling tepat.

\section{Metodologi Penelitian}

Dalam melakukan penelitian ini, metode yang dilakukan dapat dilihat pada Gambar 1 .

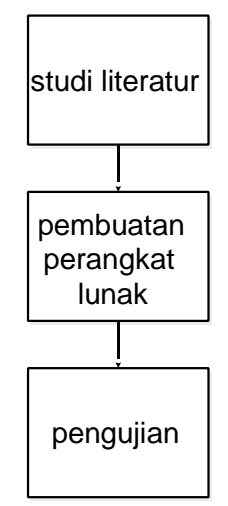

Gambar1. Metode Penelitian

1.Studi Literatur

Dasar teori dalam penelitian ini diperoleh dari referensi: buku, jurnal, artikel laporan penelitian, dan situs-situs di internet yang berkaitan dengan penelitian.

\section{Pembuatan perangkat lunak}

Adapun metodologi perancangan perangkat lunak yang dilalukan adalah metode pengembangan Waterfall.

\section{Pengujian}

Setelah melakukan perhitungan TF-IDF, maka diperoleh dokumen yang merupakan yang paling mirip atau sinonim query yang di input oleh pengguna pada sistem. Hasil pencarian yang ditampilkan sebagai sinonim kemudian dilakukan pengujian apakah sudah relevan.

Cara mengukur kualitas dari pencarian sinonim iniadalah dengan menggunakan precision dan recall. Dalam uji coba dilakukan pencocokan query pada data di database. Pengujian dilakukan terhadap 500 buah query (kata) bahasa Dayak Ngaju. Untuk mengetahui kemampuan sistem yang diusulkan dilakukan perhitungan nilai presisi dan recall terhadap 100 kali uji coba dengan query yang berbeda. Dan pengujian hasil pencarian juga akan dibantu oleh ahli bahasa Dayak ngaju untuk memperoleh hasil yang benarbenar akurat.

\section{HASIL DAN PEMBAHASAN}

\subsection{Tahapan Pencarian Sinonim}

Langkah-langkah pencarian sinonim pada kamus Bahasa Dayak Ngaju adalah sebagai berikut.

1. Menerapkan Text Processing

a. Tokenization

Pada proses tokenization setiap kata dipisahkan dan menghilangkan tanda baca atau karakter serta mengubah setiap huruf besar menjadi huruf kecil.Contoh hasil tokenization dapat dilihat pada Tabel 1. 
Tabel 1. Contoh Hasil Tokenization

\begin{tabular}{ll}
\hline D1 & $\begin{array}{l}\text { bumbu penyedap masakan yang dibuat dari } \\
\text { ikan kecil kecil atau udang yang dilumatkan } \\
\text { halus halus belacan }\end{array}$ \\
\hline D2 & $\begin{array}{l}\text { bumbu penyedap masakan yang dibuat dari } \\
\text { ikan kecil kecil atau udang yang dilumatkan } \\
\text { halus halus belacan }\end{array}$ \\
\hline D3 & $\begin{array}{l}\text { bumbu penyedap masakan yang dibuat dari } \\
\text { ikan kecil kecil atau udang yang dilumatkan } \\
\text { halus halus belacan }\end{array}$ \\
\hline D4 & $\begin{array}{l}\text { bumbu penyedap masakan yang dibuat dari } \\
\text { ikan kecil kecil atau udang yang dilumatkan } \\
\text { halus halus belacan }\end{array}$ \\
\hline
\end{tabular}

\section{b. Stopwords Removal}

Langkah berikutnya adalah menghilangkan stopwords atau kata-kata yang tidak terlalu penting.Adapun daftar stopwords yang dihapus sesuai pada stopwords list yaitu: yang, dari, dan atau.Tabel 2 menunjukkan hasil proses penghilangan stopwords.

Tabel 2. Contoh Hasil Stopwords Removal

\begin{tabular}{ll}
\hline D1 & $\begin{array}{l}\text { bumbu penyedap masakan dibuat ikan } \\
\text { kecil kecil udang dilumatkan halus halus } \\
\text { belacan }\end{array}$ \\
\hline D2 & $\begin{array}{l}\text { bumbu penyedap masakan dibuat ikan } \\
\text { kecil kecil udang dilumatkan halus halus } \\
\text { belacan }\end{array}$ \\
\hline D3 & $\begin{array}{l}\text { bumbu penyedap masakan dibuat ikan } \\
\text { kecil kecil udang dilumatkan halus halus } \\
\text { belacan }\end{array}$ \\
\hline D4 & $\begin{array}{l}\text { bumbu penyedap masakan dibuat ikan } \\
\text { kecil kecil udang dilumatkan halus halus } \\
\text { belacan }\end{array}$ \\
\hline
\end{tabular}

\section{c. Stemming}

Pada proses stemming, setiap kata akan di kembalikan ke kata akar dengan menggunakan aturan Porter Stemmer untuk Bahasa Indonesia. Contoh hasil stemming menggunakan aturan Porter Stemmer untuk Bahasa Indonesia dapat dilihat pada Tabel 4.

Tabel 4. Contoh Hasil Stemming

\begin{tabular}{cl}
\hline D1 & $\begin{array}{l}\text { bumbu sedap masa buat ikan kecil kecil } \\
\text { udang lumat halus halus belac }\end{array}$ \\
\hline D2 & $\begin{array}{l}\text { bumbu sedap masa buat ikan kecil kecil } \\
\text { udang lumat halus halus belac }\end{array}$ \\
\hline D3 & $\begin{array}{l}\text { bumbu sedap masa buat ikan kecil kecil } \\
\text { udang lumat halus halus belac }\end{array}$ \\
\hline D4 & $\begin{array}{l}\text { bumbu sedap masa buat ikan kecil kecil } \\
\text { udang lumat halus halus belac }\end{array}$ \\
\hline
\end{tabular}




\section{JURNAL TEKNOLOGI INFORMASI}

[E-ISSN 2656-0321]

[Vol 12. No. 1]

Jurnal Keilmuan dan Aplikasi Bidang Teknik Informatilka

[Januari 2018]

2. Pembobotan TF/IDF

Tabel 5 menunjukkan hasil pembobotan menggunakan algoritma TF-IDF

Tabel 5. Perhitungan TF-IDF

\begin{tabular}{|c|c|c|c|c|c|c|c|c|c|c|c|}
\hline \multirow{2}{*}{ term } & \multicolumn{4}{|c|}{ TF } & \multirow{2}{*}{ DF } & \multirow{2}{*}{$\mathrm{D} / \mathrm{DF}$} & \multirow{2}{*}{ IDF+1 } & \multicolumn{4}{|c|}{$\mathrm{W}=\mathrm{TF} *(\mathrm{IDF}+1)$} \\
\hline & D1 & D2 & D3 & D4 & & & & D1 & D2 & D3 & D4 \\
\hline sedap & 1 & 1 & 1 & 1 & 4 & 1 & 1 & 1 & 1 & 1 & 1 \\
\hline buat & 1 & 1 & 1 & 1 & 4 & 1 & 1 & 1 & 1 & 1 & 1 \\
\hline halus & 2 & 2 & 2 & 2 & 8 & 0.5 & 0.699 & 1.398 & 11.398 & 1.398 & 1.398 \\
\hline bumbu & 1 & 1 & 1 & 1 & 4 & 1 & 1 & 1 & 1 & 1 & 1 \\
\hline masa & 1 & 1 & 1 & 1 & 4 & 1 & 1 & 1 & 1 & 1 & 1 \\
\hline ikan & 1 & 1 & 1 & 1 & 4 & 1 & 1 & 1 & 1 & 1 & 1 \\
\hline kecil & 2 & 2 & 2 & 2 & 8 & 0.5 & 0.699 & 1.398 & 11.398 & 1.398 & 1.398 \\
\hline udang & 1 & 1 & 1 & 1 & 4 & 1 & 1 & 1 & 1 & 1 & 1 \\
\hline lumat & 1 & 1 & 1 & 1 & 4 & 1 & 1 & 1 & 1 & 1 & 1 \\
\hline balac & 1 & 1 & 1 & 1 & 4 & 1 & 1 & 1 & 1 & 1 & 1 \\
\hline
\end{tabular}

bobot $(\mathrm{W})$ untuk $\mathrm{D} 1=10.796$

bobot $(\mathrm{W})$ untuk $\mathrm{D} 2=10.796$

bobot $(\mathrm{W})$ untuk $\mathrm{D} 3=10.796$

bobot $(\mathrm{W})$ untuk $\mathrm{D} 4=10.796$

Dari hasil pengurutan bobot dokumen diatas diperoleh bobot yang sama untuk setiap dokumen. Dokumen yang memiliki sinonim "acan" yang berada pada dokumen 1. sehingga diurutkan berdasarkan abjad yang ditampilkan sebagai sinonim dokumen 1, yaitu dokumen 2,3 dan 4 .

\subsection{Analisis Hasil Pengujian Kerja Sistem}

Untuk perhitungan nilai Precision dan Recallterhadap 100 kali uji coba dengan queryyang berbeda dapat dilihat secara lengkap pada Tabel 7.

Tabel 7. Perhitungan Nilai Precisiondan Recall 100 Kali Uji Coba

\begin{tabular}{ccccc}
\hline No & input & sinonim & precision & recall \\
\hline 1 & acan & $\begin{array}{c}\text { blasan } \\
\text { balasan } \\
\text { malasan }\end{array}$ & $\mathrm{P}=3 / 3=1$ & $\mathrm{R}=3 / 3=1$ \\
\hline 2 & $\begin{array}{c}\text { jukong } \\
\text { arut } \\
\text { lasang } \\
\text { alut } \\
\text { banama }\end{array}$ & $\mathrm{P}=5 / 5=1$ & $\mathrm{R}=5 / 5=1$ \\
& ajong & $\begin{array}{c}\text { ayub } \\
\text { sindah } \\
\text { daup }\end{array}$ & $\mathrm{P}=3 / 3=1$ & $\mathrm{R}=3 / 3=1$ \\
\hline 3 & iwan & & & \\
\hline
\end{tabular}




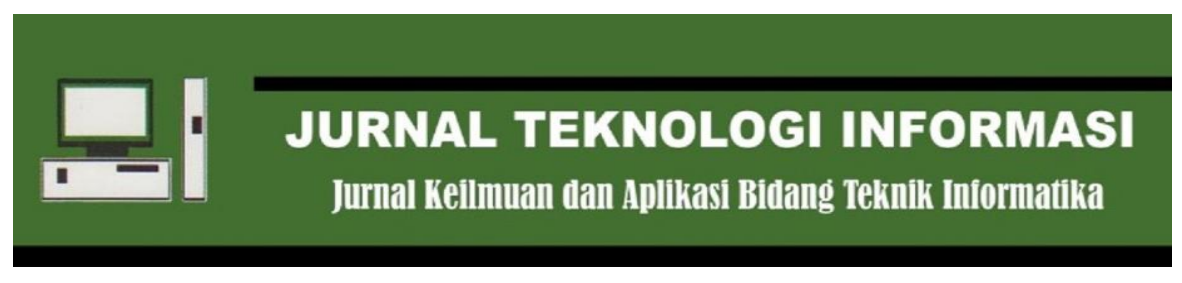

[E-ISSN 2656-0321]

[Vol 12. No. 1]

[Januari 2018]

\begin{tabular}{|c|c|c|c|c|}
\hline 4 & lilir & ririr & $\mathrm{P}=1 / 1=1$ & $\mathrm{R}=1 / 1=1$ \\
\hline 5 & jadi & jari & $\mathrm{P}=1 / 1=1$ & $\mathrm{R}=1 / 1=1$ \\
\hline 6 & jakah & abir & $\mathrm{P}=1 / 1=1$ & $\mathrm{R}=1 / 1=1$ \\
\hline 7 & bahua & taheta & $\mathrm{P}=1 / 1=1$ & $\mathrm{R}=1 / 1=1$ \\
\hline 8 & balaman & kasintu & $\mathrm{P}=1 / 1=1$ & $\mathrm{R}=1 / 1=1$ \\
\hline 9 & tabe & tabi & $\mathrm{P}=1 / 1=1$ & $\mathrm{R}=1 / 1=1$ \\
\hline 10 & rahun & $\begin{array}{l}\text { ranum } \\
\text { danum }\end{array}$ & $\mathrm{P}=2 / 2=1$ & $\mathrm{R}=2 / 2=1$ \\
\hline 11 & katuk & & $\mathrm{P}=0$ & $\mathrm{R}=0$ \\
\hline 12 & nule & & $\mathrm{P}=0$ & $\mathrm{R}=0$ \\
\hline 13 & senam & & $\mathrm{P}=0$ & $\mathrm{R}=0$ \\
\hline 14 & ambon & enon & $\mathrm{P}=1 / 1=1$ & $\mathrm{R}=1 / 1=1$ \\
\hline 15 & andap & anap & $\mathrm{P}=1 / 1=1$ & $\mathrm{R}=1 / 1=1$ \\
\hline 16 & wujud & & $\mathrm{P}=0$ & $\mathrm{R}=0$ \\
\hline 17 & pander & & $\mathrm{P}=0$ & $\mathrm{R}=0$ \\
\hline 18 & pahelat & & $\mathrm{P}=0$ & $\mathrm{R}=0$ \\
\hline 19 & bau & & $\mathrm{P}=0$ & $\mathrm{R}=0$ \\
\hline 20 & bajan & & $\mathrm{P}=0$ & $\mathrm{R}=0$ \\
\hline 21 & gambuh & & $\mathrm{P}=0$ & $\mathrm{R}=0$ \\
\hline 22 & utara & & $\mathrm{P}=0$ & $\mathrm{R}=0$ \\
\hline 23 & bahekang & & $\mathrm{P}=0$ & $\mathrm{R}=0$ \\
\hline 24 & bajai & & $\mathrm{P}=0$ & $\mathrm{R}=0$ \\
\hline 25 & mujur & & $\mathrm{P}=0$ & $\mathrm{R}=0$ \\
\hline 26 & katarangan & & $\mathrm{P}=0$ & $\mathrm{R}=0$ \\
\hline 27 & umpamae & & $\mathrm{P}=0$ & $\mathrm{R}=0$ \\
\hline 28 & labih & & $\mathrm{P}=0$ & $\mathrm{R}=0$ \\
\hline 29 & uret & & $\mathrm{P}=0$ & $\mathrm{R}=0$ \\
\hline 30 & handipe & & $\mathrm{P}=0$ & $\mathrm{R}=0$ \\
\hline 31 & takiri & & $\mathrm{P}=0$ & $\mathrm{R}=0$ \\
\hline 32 & anggih & ayun & $\mathrm{P}=1 / 1=1$ & $\mathrm{R}=1 / 1=1$ \\
\hline 33 & panga & & $\mathrm{P}=0$ & $\mathrm{R}=0$ \\
\hline 34 & aduk & & $\mathrm{P}=0$ & $\mathrm{R}=0$ \\
\hline 35 & uras & & $\mathrm{P}=0$ & $\mathrm{R}=0$ \\
\hline \multirow[t]{2}{*}{36} & \multirow[t]{2}{*}{ badurok } & hantuen & $\mathrm{P}=2 / 2=1$ & $\mathrm{R}=2 / 2=1$ \\
\hline & & hantimang & $\mathrm{P}=1 / 1=1$ & $\mathrm{R}=1 / 1=1$ \\
\hline 37 & gilau & gau & $\mathrm{P}=1 / 1=1$ & $\mathrm{R}=1 / 1=1$ \\
\hline 38 & ginau & ginyau & $\mathrm{P}=1 / 1=1$ & $\mathrm{R}=1 / 1=1$ \\
\hline 39 & gohap & jowoi & $\mathrm{P}=1 / 1=1$ & $\mathrm{R}=1 / 1=1$ \\
\hline 40 & gohong & & $\mathrm{P}=0$ & $\mathrm{R}=0$ \\
\hline 41 & iner & & $\mathrm{P}=0$ & $\mathrm{R}=0$ \\
\hline 42 & balawang & & $\mathrm{P}=0$ & $\mathrm{R}=0$ \\
\hline 43 & tungkeh & & $\mathrm{P}=0$ & $\mathrm{R}=0$ \\
\hline 44 & turus & & $\mathrm{P}=0$ & $\mathrm{R}=0$ \\
\hline 45 & lunju & & $\mathrm{P}=0$ & $\mathrm{R}=0$ \\
\hline 46 & tungkeh & & $\mathrm{P}=0$ & $\mathrm{R}=0$ \\
\hline 47 & sadar & & $\mathrm{P}=0$ & $\mathrm{R}=0$ \\
\hline 48 & bane & bana & $\mathrm{P}=1 / 1=1$ & $\mathrm{R}=1 / 1=1$ \\
\hline 49 & sunto & & $\mathrm{P}=0$ & $\mathrm{R}=0$ \\
\hline 50 & dawat & & $\mathrm{P}=0$ & $\mathrm{R}=0$ \\
\hline 51 & gantong & & $\mathrm{P}=0$ & $\mathrm{R}=0$ \\
\hline 52 & gawi & & $\mathrm{P}=0$ & $\mathrm{R}=0$ \\
\hline 53 & baha & & $\mathrm{P}=0$ & $\mathrm{R}=0$ \\
\hline 54 & uhat & & $\mathrm{P}=0$ & $\mathrm{R}=0$ \\
\hline 55 & umur & & $\mathrm{P}=0$ & $\mathrm{R}=0$ \\
\hline 56 & kasintu & balaman & $\mathrm{P}=1 / 1=1$ & $\mathrm{R}=1 / 1=1$ \\
\hline 57 & tunju & & $\mathrm{P}=0$ & $\mathrm{R}=0$ \\
\hline 58 & balok & kahau & $\mathrm{P}=1 / 1=1$ & $\mathrm{R}=1 / 1=1$ \\
\hline 59 & balon & galembong & $\mathrm{P}=1 / 1=1$ & $\mathrm{R}=1 / 1=1$ \\
\hline
\end{tabular}




\section{JURNAL TEKNOLOGI INFORMASI}

[E-ISSN 2656-0321]

[Vol 12. No. 1]

Jurnal Keilmuan dan Aplikasi Bidang Teknik Informatilka

[Januari 2018]

\begin{tabular}{|c|c|c|c|c|}
\hline 60 & himun & & $\mathrm{P}=0$ & $\mathrm{R}=0$ \\
\hline 61 & tatawe & & $\mathrm{P}=0$ & $\mathrm{R}=0$ \\
\hline 62 & bangang & busik & $\mathrm{P}=1 / 1=1$ & $\mathrm{R}=1 / 1=1$ \\
\hline 63 & babang & ridu & $\mathrm{P}=1 / 1=1$ & $\mathrm{R}=1 / 1=1$ \\
\hline 64 & tumbah & & $\mathrm{P}=0$ & $\mathrm{R}=0$ \\
\hline 65 & dahian & & $\mathrm{P}=0$ & $\mathrm{R}=0$ \\
\hline 66 & tatarik & & $\mathrm{P}=0$ & $\mathrm{R}=0$ \\
\hline 67 & tajaga & & $\mathrm{P}=0$ & $\mathrm{R}=0$ \\
\hline 68 & dadau & rau & $\mathrm{P}=1 / 1=1$ & $\mathrm{R}=1 / 1=1$ \\
\hline 69 & taimbing & & $\mathrm{P}=0$ & $\mathrm{R}=0$ \\
\hline 70 & damar & nyating & $\mathrm{P}=1 / 1=1$ & $\mathrm{R}=1 / 1=1$ \\
\hline 71 & adil & & $\mathrm{P}=0$ & $\mathrm{R}=0$ \\
\hline 72 & akik & & $\mathrm{P}=0$ & $\mathrm{R}=0$ \\
\hline 73 & lapik & & $\mathrm{P}=0$ & $\mathrm{R}=0$ \\
\hline 74 & capak & dampah & $\mathrm{P}=1 / 1=1$ & $\mathrm{R}=1 / 1=1$ \\
\hline 75 & dampahan & & $\mathrm{P}=1 / 1=1$ & $\mathrm{R}=1 / 1=1$ \\
\hline 76 & duhi & dahiang & $\mathrm{P}=1 / 1=1$ & $\mathrm{R}=1 / 1=1$ \\
\hline 77 & riwut & & $\mathrm{P}=0$ & $\mathrm{R}=0$ \\
\hline 78 & ikau & & $\mathrm{P}=0$ & $\mathrm{R}=0$ \\
\hline 79 & gadur & kandarah & $\mathrm{P}=1 / 1=1$ & $\mathrm{R}=1 / 1=1$ \\
\hline 80 & gagelan & Kagelan & $\mathrm{P}=1 / 1=1$ & $\mathrm{R}=1 / 1=1$ \\
\hline 81 & garanat & manas & $\mathrm{P}=1 / 1=1$ & $\mathrm{R}=1 / 1=1$ \\
\hline 82 & gigir & gawing & $\mathrm{P}=1 / 1=1$ & $\mathrm{R}=1 / 1=1$ \\
\hline 83 & pantatan & & $\mathrm{P}=0$ & $\mathrm{R}=0$ \\
\hline 84 & tanggoi & & $\mathrm{P}=0$ & $\mathrm{R}=0$ \\
\hline 85 & topang & & $\mathrm{P}=0$ & $\mathrm{R}=0$ \\
\hline 86 & topeng & & $\mathrm{P}=0$ & $\mathrm{R}=0$ \\
\hline 87 & turus & & $\mathrm{P}=0$ & $\mathrm{R}=0$ \\
\hline 88 & jabong & & $\mathrm{P}=0$ & $\mathrm{R}=0$ \\
\hline 89 & laga & & $\mathrm{P}=0$ & $\mathrm{R}=0$ \\
\hline 90 & ongko & & $\mathrm{P}=0$ & $\mathrm{R}=0$ \\
\hline 91 & haga & & $\mathrm{P}=0$ & $\mathrm{R}=0$ \\
\hline 92 & bahari & & $\mathrm{P}=0$ & $\mathrm{R}=0$ \\
\hline 93 & pahir & & $\mathrm{P}=0$ & $\mathrm{R}=0$ \\
\hline 94 & antang & & $\mathrm{P}=0$ & $\mathrm{R}=0$ \\
\hline 95 & penda & & $\mathrm{P}=0$ & $\mathrm{R}=0$ \\
\hline 96 & aba & abai & $\mathrm{P}=1 / 1=1$ & $\mathrm{R}=1 / 1=1$ \\
\hline 97 & asep & & $\mathrm{P}=0$ & $\mathrm{R}=0$ \\
\hline 98 & ampit & & $\mathrm{P}=0$ & $\mathrm{R}=0$ \\
\hline 99 & sahap & tatudong & $\mathrm{P}=1 / 1=1$ & $\mathrm{R}=1 / 1=1$ \\
\hline 100 & manok & & $\mathrm{P}=0$ & $\mathrm{R}=0$ \\
\hline
\end{tabular}

Dari Tabel 7, hasil pengujian dengan precision dan recall untuk 100 query berbeda yang diinput diperoleh query yang memiliki sinonim sebanyak 33 query. Sehingga diperoleh rata-rata hasil pencarian sinonim adalah:

Rata-rata pencarian sinonim $=\frac{33}{100} \times 100=33 \%$

Hasil perhitungan rata-rata pencarian sinonim diperoleh 33\% karena 67 query lain tidak ditemukan sinonimnya. Hal ini terjadi karena data didalam database belum lengkap. 


\section{Kesimpulan}

Dari hasil penelitian, dapat disimpulkan beberapa hal sebagai berikut.

1. Untuk pencarian sinonim dari 100 query yang dimasukkan dan yang memiliki sinonim adalah 33 query dan diperoleh nilai Precision $=1$ dan Recall $=1$.

2. Hasil perhitungan rata-rata pencarian sinonim diperoleh $33 \%$.

3. Relevansi dalam pencarian sinonim $100 \%$ tepat, artinya kualitas sistem dalam pencarian sangat baik.

\section{DAFTAR PUSTAKA}

[1] Indriyono Bonifacius Vicky, Utami Ema, Sunyoto

Andi. 2015. Pemanfaatan Algoritma Porter Stemmer Untuk Bahasa Indonesia Dalam Proses Klasifikasi Jenis Buku. Program Pascasarjana Magister Teknik Informatika STMIK AMIKOM. Yogyakarta.

[2] Iper, Dunis.2009.Kamus Bahasa Dayak Ngaju-Indonesia. Palangkaraya: C.V. Anugrah Indah Mandiri. Iper, Dunis., Alexander, Darius Karel. 2016. Kosakata Bahasa Indonesia-Dayak Ngaju. Palangkaraya: C.V. Anugrah Indah Mandiri

[4] Jogiyanto Hartono, 2005.Analisis dan Desain Sistem Informasi. Yogyakarta: Andi

[4] Dharwiyanti, Sri dan Satria W, Romi. 2003. Pengantar Unified Modeling Language(UML).http://www.IlmuKomputer.com. Diakses pada tanggal 26 September 2017.

[5] Dermawani, Novalina S. 2008. Aplikasi Web Dinamis Menggunakan Php dan Mysql pada International Education Centre, Inc.USU.Medan. (Http ://Repository.Usu.Ac.Id/Bitstream /123456789/14004/1/09e00318.P df). Diakses pada tanggal 21 November 2016

[6] Sholihin, Andi. 2012.Program Stemming Bahasa Indonesia Dengan Algoritma Porter Berbasis Web dengan PHP \& MySQL.

[7] Utami, Retno. 2010. Kajian Sinonim Nomina Dalam Bahasa Indonesia. Universitas Sebelas Maret. Suraka rta. (http://eprints.uns.ac.id/9073/ 1/149581708201005051.pdf). Diakses pada tanggal 21 September 2017. 